\title{
PERANCANGAN FILM DOKUMENTER BATA BETON BERBAHAN DASAR SAMPAH PLASTIK SEBAGAI BAHAN BANGUNAN RAMAH LINGKUNGAN
}

\author{
Ismiliana Eka Saputri ${ }^{1)}$, Ndaru Ranuhandoko ${ }^{2)}$, Wulandari $^{3)}$ \\ Program Studi Desain Komunikasi Visual, \\ Fakultas Bahasa dan Seni, Universitas Indraprasta PGRI \\ Jl. Nangka No. 58 C, Tanjung Barat, Jakarta Selatan, 12530, Indonesia \\ Email: ndaruranuhandoko1969@gmail.com
}

\begin{abstract}
Abstrak
Tujuan penelitian yaitu untuk merancang film dokumenter paving block berbahan dasar sampah plastik sebagai bahan bangunan ramah lingkungan. Film dokumenter ini diharapkan dapat menyadarkan masyarakat tentang pentingnya mengelola sampah plastik. Metode penelitian yang digunakan adalah metode penelitian kualitatif, dalam penelitian kualitatif dilakukan dengan mendeskripsikan data dari studi literatur, observasi langsung ke lapangan dan wawancara dengan narasumber yang sesuai dengan bidangnya. Berdasarkan data yang diperoleh dari berbagai sumber, paving block berbahan dasar sampah plastik dapat membantu menekan/mengurangi keberadaan sampah plastik. Dengan mengelola sampah plastik, masyarakat dapat berkontribusi dalam menjaga lingkungan dari dampak yang dapat dihasilkan dari sampah plastik. Dalam data yang diteliti, permasalahan yang signifikan ialah minimnya kesadaran masyarakat dalam pengelolaan sampah. Peneliti bermaksud untuk merancang sebuah media visual yang dapat dimengerti dan dipahami oleh masyarakat yang dituju. Hasil rancangan yang dibuat berupa film dokumenter yang dapat membuat masyarakat mengetahui bahwa sampah plastik dapat dimanfaatkan dan mendorong masyarakat untuk ikut serta tertarik dalam mengelola sampah plastik sehingga sampah plastik dapat dijadikan suatu produk yang memiliki nilai jual.
\end{abstract}

Kata Kunci: Film Dokumenter, Bata Beton Plastik, Bahan Bangunan, Ramah Lingkungan.

\begin{abstract}
The research objective is to design a documentary film on paving blocks made from plastic waste as an environmentally friendly building material. This documentary film is expected to make people aware of the importance of managing plastic waste. The research method used is qualitative research methods, in qualitative research is done by describing data from literature studies, direct observation to the field and interviews with informants who are in accordance with their fields. Based on data obtained from various sources, paving blocks made from plastic waste can help suppress / reduce the presence of plastic waste. By managing plastic waste, people can contribute to protecting the environment from the impacts that plastic waste can produce. In the data studied, a significant problem is the lack of public awareness of waste management. The researcher intends to design a visual media that can be understood and understood by the target community. The design results are made in the form of a documentary film that can make people know that plastic waste can be used and encourage people to be interested in managing plastic waste so that plastic waste can be used as a product that has a sale value.
\end{abstract}

Keywords: Documentary Film, Plastic Concrete Bricks, Building Materials, Environmentally Friendly.

Correspondence author: Ndaru Ranuhandoko, ndaruranuhandoko1969@ gmail.com, Jakarta, Indonesia. 


\section{PENDAHULUAN}

Plastik adalah sebuah bahan yang sering dipakai untuk membuat beberapa benda atau barang yang digunakan dalam sehari-hari, seperti kantong plastik, kemasan plastik, dan lain-lain. Plastik menjadi sering digunakan karena harga plastik yang murah, sifatnya yang ringan dan mudah untuk dibawa ke mana pun (fleksibel). Penggunaan plastik menjadi hal yang wajar dan dapat membantu manusia dalam setiap aktivitas. Namun, plastik yang sudah tidak terpakai akan menjadi sampah yang akan sulit untuk terurai di dalam tanah dan dapat menjadi bencana untuk manusia itu sendiri.

Menurut Harian Kompas dalam Sundawa dan Pramushinta, sampah plastik di Indonesia telah mencatatkan rekor sebagai negaraterbesar kedua penyumbang sampah plastik di dunia. INAPLAS (Asosiasi Industri Plastik Indonesia) menambahkan setiap tahunnya, Indonesia menyumbang 10 miliar lembar plastik atau sekitar 85.000 ton sampah kantong plastik (Sundawa \& Pramushinta, 2019:17). Indonesia masih tertinggal dalam pengelolaan sampah, karena masyarakatnya masih terbilang minim kesadaran terhadap sampah (Candraditya, 2018). Sampah plastik memiliki sifat sukar diuraikan dalam tanah dan membutuhkan waktu 20 hingga 100 tahun untuk terurai dalam tanah dengan sempurna (Gusniar, 2018: 130).

Salah satu produk daur ulang yang memanfaatkan sampah plastik sebagai bahan dasar pembuatannya adalah paving block. Paving block atau sering disebut dengan bata beton adalah bahan bangunan yang digunakan untuk menutup permukaan jalan. Bata beton dikenal dengan mempunyai penyerapan air yang baik di antara pengerasan jalan lainnya. Menurut Sibuea, tingginya permintaan konsumen terhadap bata beton tidak diimbangi dengan ketersediaan kualitas yang memadai baik dari segi kekuatan, umur pakai, dan durability bata beton. Banyak bata beton yang dijumpai pada permukaan jalan mengalami retak-retak, mudah patah, banyakditumbuhi oleh lumut, karena bata beton bersifat getas (Sibuea, 2013:2).

Berdasarkan wawancara dengan Badru Hidayat selaku Pemilik Produksi Bata Beton Plastik dan Ketua Bank Sampah Nurul Fikri 14.12 pada tanggal 14 Desember 2019, bata beton plastik telah diuji coba oleh Balai Litbang Teknik Lalu Lintas dan Lingkungan Bandung dan mampu bertahan selama 5 tahun pemakaian. Bata beton plastik telah dipakai di sekitar jalan perkampungan di Kecamatan Gedebage, Kota Bandung, Jawa Barat.

Dari data tersebut, dibutuhkannya media film dokumenter untuk menyadarkan masyarakat tentang pentingnya mengelola sampah plastik. Film memiliki potensi untuk mempengaruhi khalayaknya. Film juga menjadi sarana penyampaian pesan yang dapat diterima dengan cepat (Mudjiono, 2011: 130).

Berdasarkan hasil pengamatan peneliti, media informasi tentang bata beton berbahan dasar sampah plastik sudah terdapat pada artikel berita, buku,dan youtube. Dengan adanya media tersebut, masyarakat dapat mengakses dengan cepat dan mudah. Namun media tersebut hanya memberikan informasi tentang adanya/keberadaan bata beton yang terbuat dari sampah plastik.

Peneliti bermaksud untuk merancang film dokumenter bata beton berbahan dasar sampah plastik yang bukan hanya sekadar untuk informasi terhadap masyarakat tetapi dapat memotivasi masyarakat untuk ikut tertarik mengelola sampah plastik sehingga sampah plastik dapat dijadikan suatu produk yang memiliki nilai jual.

Film dokumenter yang dibuat menggunakan beberapa teknik pengambilan gambar eye level dan high angle dan juga teknik pergerakan kamera dengan ukuran gambar extreme long shot, long shot, medium long shot, medium shot dan close up.

\section{METODE PENELITIAN}

Jenis penelitian ini menggunakan metode kualitatif. Penelitian kualitatif banyak digunakan dalam penelitian sosial. Penelitian kualitatif merupakan suatu penelitian yang hasil penelitiannya tidak diperoleh melalui prosedur statistik atau metode kuantifikasi yang lain (Anggito \& Setiawan, 2018: 8). Metode kualitatif adalah jenis penelitian yang bentuknya pengukuran dengan data deskripsi. Dipilihnya metode kualitatif ini karena penelitian dilakukan dengan mendeskripsikan data dari studi literatur, observasi dan wawancara dengan narasumber 
yang sesuai dengan bidangnya. Data yang telah dikumpulkan akan menjadi referensi untuk merancang film dokumenter bata beton berbahan dasar sampah plastik sebagai bahan bangunan ramah lingkungan.

\section{HASIL DAN PEMBAHASAN}

\section{Sampah Plastik}

Plastik merupakan bahan baru yang semakin berkembang. Plastik banyak digunakan untuk berbagai macam bahan dasar. Penggunaan plastikdapat dipakai sebagai bahan pengemas, konstruksi, elektroteknik, automotif, mebel, pertanian, peralatan rumah tangga, bahan pesawat, kapalmainan dan lain sebagainya. Penggunaan plastik di berbagai bidang seperti di atas didasarkan pada alasan bahwa bahan plastik mempunyai keunggulan dibandingkan dengan bahan lain antara lain, seperti tidak mudah berkarat, kuat, tidak mudah pecah, ringan, dan elastis (Amran, 2015: 127).

Berbagai industri di dunia menggunakan plastik untuk mengemas produk mereka. Industri makanan dan minuman instan misalnya, memilih plastik berlapis alumunium foil atau plastik multilayer sebagai kemasan karena dianggap aman dan dapat menjaga produk tetap layak dikonsumsi. Di samping itu, material pembungkus ini tidak membuat biaya produksi melonjak. Produsen tetap dapat menjual produk eceran dengan harga yang terjangkau. Hal yang sama juga dilakukan oleh produsen shampo, permen, susu dan obat-obatan. Plastik kemasan berlapis alumunium foil menggantikan kaca, kaleng, dan kertas sebagai material pengemas (Putra \& Yuriandala, 2010: 22).

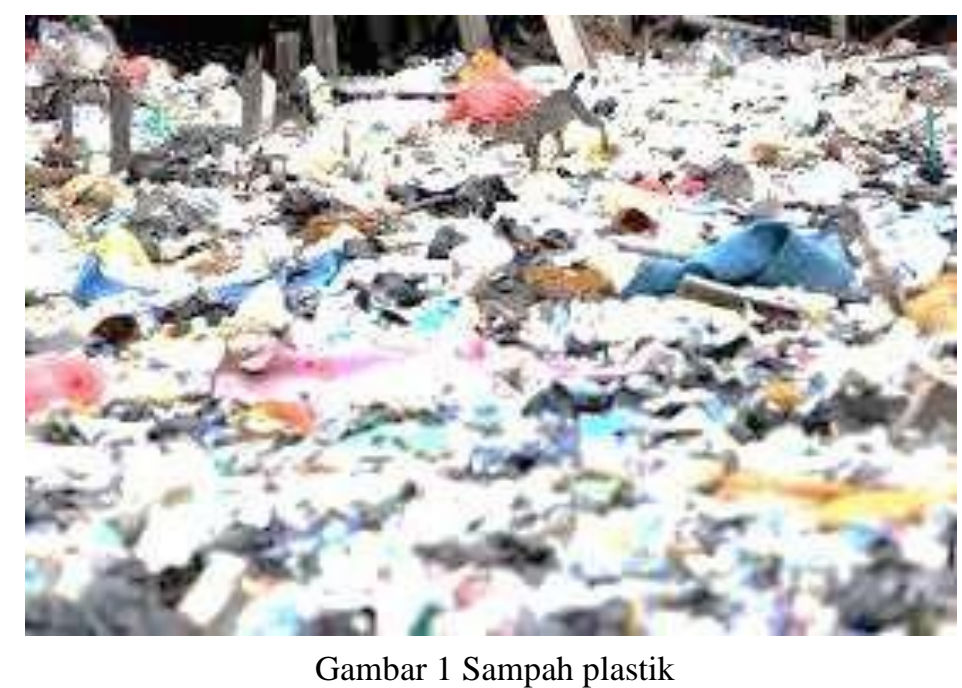

Permasalahan sampah di Indonesia merupakan masalah yang belumterselesaikan hingga saat ini, sementara itu dengan bertambahnya jumlah penduduk maka akan mengikuti pula bertambahnya volume timbulan sampah yang dihasilkan dari aktivitas manusia. Komposisi sampah yang dihasilkan dari aktivitas manusia adalah sampah organik sebanyak $60-70 \%$ dan sisanya adalah sampah non organik 30-40\%, sementara itu dari sampah non organik tersebut komposisi sampah terbanyak kedua yaitu sebesar $14 \%$ adalah sampah plastik. Sampah plastik yang terbanyak adalah jenis kantong plastik atau kantong kresek selain plastik kemasan (Purwaningrum, 2016: 142).

\section{Bata Beton}

Menurut Husin dalam Amran bata beton untuk lantai (paving block) adalah suatu elemen bahan bangunan yang dibuat dari campuran semen hidroulis atau sejenisnya, agregat halus dan air dengan atau dengan bahan tambahan lainnya yang tidak mengurangi mutu bata beton 
(paving block) tersebut. Bata Beton disebut juga interblock concrete, sudah sejak tahun 1950-an telah dipakai secara luas di negeri Belanda sebagai pengganti batu bata konvensional untuk pekerjaan jalan (Amran, 2015: 125).

Bata Beton adalah suatu komposisi bahan bangunan yang dibuat daricampuran semen portland atau bahan perekat hidrolis sejenis, air, dan agregat dengan atau bahan tambah lainnya yang tidak mengurangi mutu bata beton itu. Bata Beton dapat digunakan di sekitar lingkungan rumah dan kantor. Fungsi utama bahan ini adalah untuk menutup lantai dalam jangka waktu yang lama (Sumarni, 2016: 111).

Bata Beton atau konblok sekarang banyak digunakan oleh kontraktor dan developer. Hal ini dikarenakan adanya peraturan pemerintah yang mempersyaratkan resapan air untuk bangunan gedung, perumahan danlainnya. Karena bata beton bermanfaat dan berfungsi untuk resapan air dan keindahan tampilannya karena banyak model yang ditawarkan dibandingkan dengan perkerasan lahan dengan menggunakan aspal hotmix ataupun cor beton readymix (Hamidah, 2018: 113).

\section{Konsep Perancangan}

Konsep media meliputi rincian langkah-langkah dalam merancang sebuah media. Rincian ini untuk mempermudah menulis perancangan karya desain. Adapun konsep media yang digunakan dalam film dokumenter ini, diantaranya. Judul film dokumenter yang akan dibuat adalah "Sampah Plastik, Kawan atau Lawan?". Dalam film dokumenter ini, menunjukkan bahwa sampah plastik dapat menjadi kawan atau lawan sesuai dengan sikap danperilaku masyarakat itu sendiri. Film dokumenter akan dibuat dengan frame size 16:9 yaitu 1920x1080 pixels full HD dengan output $\mathrm{H} .264$ dengan format file mp4,dengan durasi film 7 menit.

\section{Mind Mapping}

Mind mapping biasa digunakan sebagai pemetaan pikiran untuk mengelola sebuah informasi sebagai berikut:

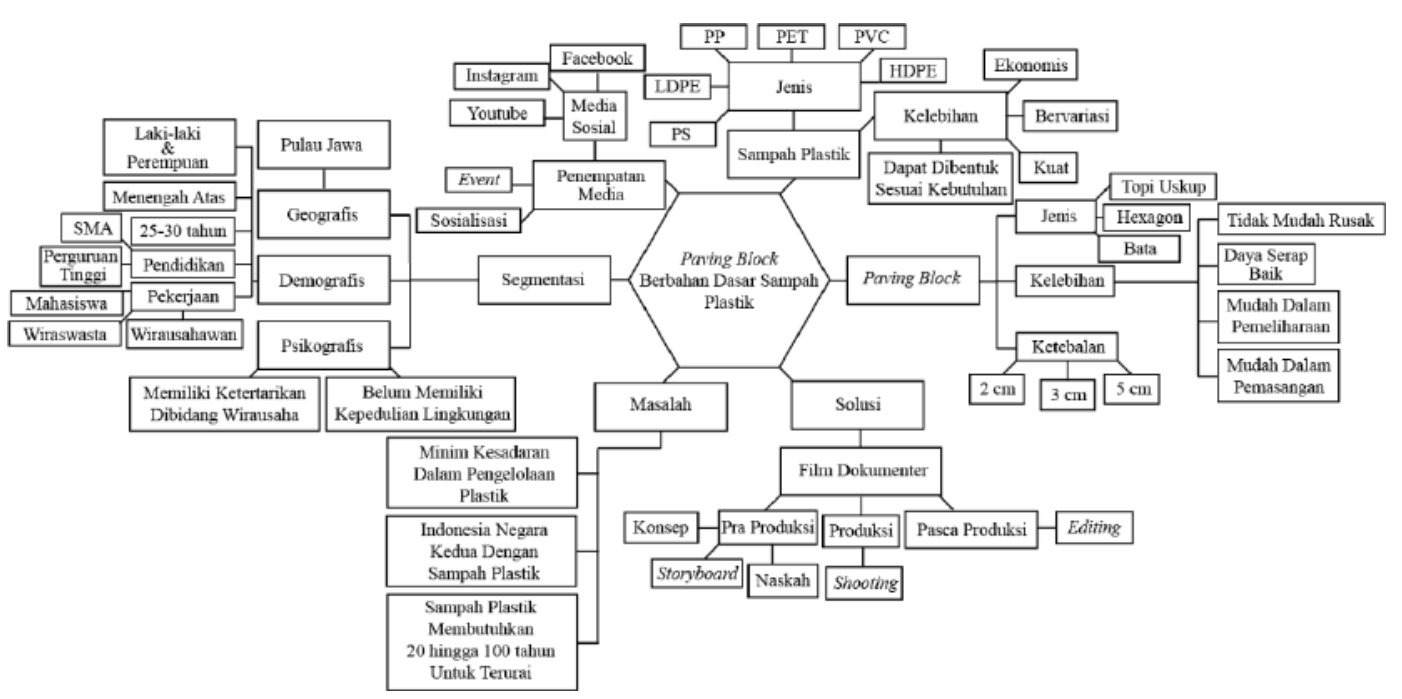

\section{Mood board}

Gambar 2 Mind Mapping

Mood board adalah gabungan dari beberapa gambar atau visual yang dapat mengacu pada konsep gaya visual, yang di dalamnya mencakup gaya ilustrasi, warna, huruf, dan elemen lain yang mempengaruhi hasil akhir tampilan film, dan dapat menjadi referensi atau acuan dalam pembuatan film. 


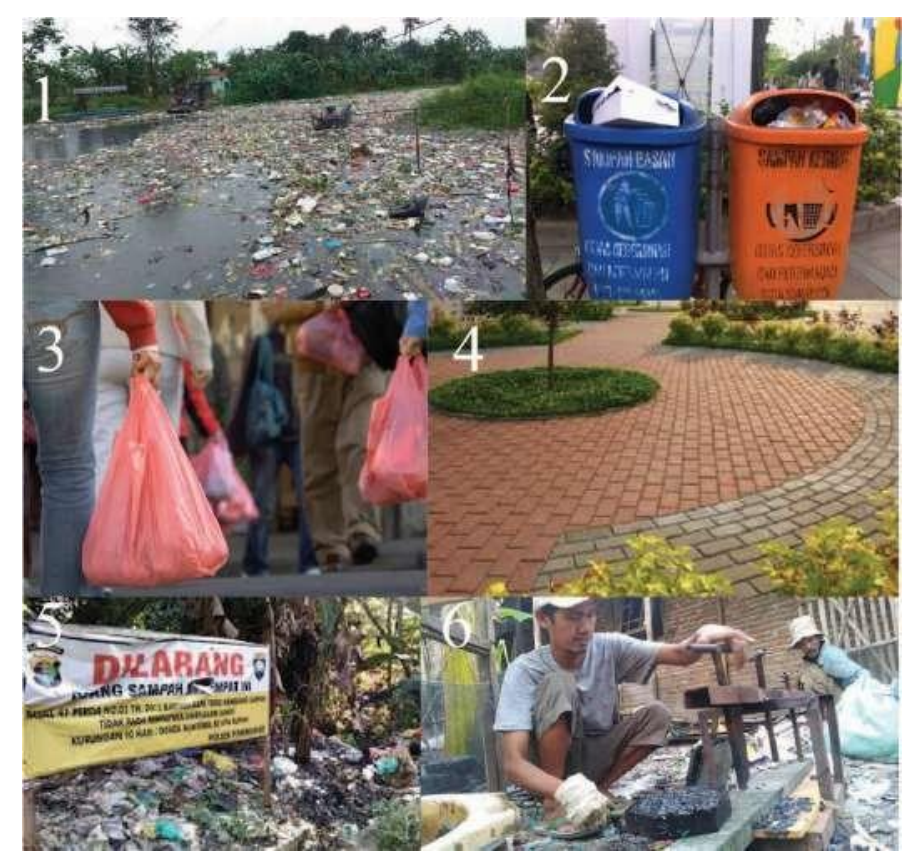

Gambar 3 Mood board

\section{Storyboard}

Storyboard adalah serangkaian gambar yang dibuat untuk membantu para film maker memahami alur cerita, angle kamera, durasi film, dan lainnya.

\begin{tabular}{|c|c|c|c|}
\hline Segment & Sketsa, Durasi, dan Angle & Adegan dan Scene & $\begin{array}{c}\text { Voice Over, Sound Effect, } \\
\text { Narasi }\end{array}$ \\
\hline 1 & $\begin{array}{c}S_{\text {Sam Pah Pcastjk }} \\
\text { khwan Atau Lawan? } \\
00: 00: 00: 00-00: 00: 07: 00\end{array}$ & Opening film & Musik instrumen \\
\hline 2 & 00:00:07:01-00:00:10:00 & $\begin{array}{l}\text { Penggunaan plastik } \\
\text { sehari-hari }\end{array}$ & $\begin{array}{l}\text { Musik instrumen dan narasi: } \\
\text { Plastik telah menjadi kebutuhan } \\
\text { manusia yang sangat penting di } \\
\text { segala bidang }\end{array}$ \\
\hline 3 & $\begin{array}{l}\text { (Medium Shot) } \\
\text { 00:00:10:01-00:00:19:00 }\end{array}$ & $\begin{array}{l}\text { Plastik yang } \\
\text { digunakan hampir di } \\
\text { berbagai aktivitas }\end{array}$ & $\begin{array}{l}\text { Musik instrumendan narasi: } \\
\text { Setiap hari pun kitapasti } \\
\text { menggunakanplastik dalam } \\
\text { setiap aktivitas }\end{array}$ \\
\hline 4 & & $\begin{array}{l}\text { Plastik yang menjadi } \\
\text { pilihan semua orang } \\
\text { dalam membungkus } \\
\text { makanan }\end{array}$ & $\begin{array}{l}\text { Musik instrumen dan narasi: } \\
\text { Harganya yang murah menjadi } \\
\text { salah satu pilihan banyak orang, } \\
\text { sifatnya yang ringan dan mudah } \\
\text { dibawa ke mana pun menjadi } \\
\text { alasan setiap orang }\end{array}$ \\
\hline
\end{tabular}




\begin{tabular}{|c|c|c|c|}
\hline & $\begin{array}{l}\text { (Extreme Long Shot, Long Shot, } \\
\text { Medium Shot) 00:00:19:01- } \\
\text { 00:00:29:00 }\end{array}$ & & menggunakan plastik \\
\hline 5 & 00:00:29:01-00:00:34:00 & $\begin{array}{l}\text { Plastik yang dipakai } \\
\text { dan plastik yang } \\
\text { sudah tidak dipakai }\end{array}$ & $\begin{array}{l}\text { Musik instrumendan narasi: } \\
\text { Tanpa disadari, plastik yang } \\
\text { sudah tidak digunakan dapat } \\
\text { menjadi ancaman }\end{array}$ \\
\hline 6 & $\begin{array}{l}\text { Dilarang! } \\
\text { Shot, MediumShot) } \\
\text { 00:00:34:01-00:00:40:00 }\end{array}$ & $\begin{array}{l}\text { Sampah yangdibuang } \\
\text { sembarangan }\end{array}$ & $\begin{array}{l}\text { Musik instrumen dan narasi: } \\
\text { Yang awalnya menjadi kawan } \\
\text { bisa berubah menjadi lawan. }\end{array}$ \\
\hline 7 & $\begin{array}{l}\text { (Long Shot) } \\
\text { 00:00:40:01-00:00:44:00 }\end{array}$ & $\begin{array}{l}\text { Sampah yang hanya } \\
\text { dibiarkan sehingga } \\
\text { menumpuk }\end{array}$ & $\begin{array}{l}\text { Musik instrumen dan narasi: } \\
\text { Bagi manusia itu sendiri dan } \\
\text { lingkungan sekitar. }\end{array}$ \\
\hline 8 & $\begin{array}{l}\text { Menurut daes A Sosiasi } \\
\text { sumber: } \\
00: 00: 44: 01-00: 00: 51: 00\end{array}$ & $\begin{array}{l}\text { Data Sampah Plastik } \\
\text { di Indonesia }\end{array}$ & $\begin{array}{l}\text { Musik instrumen dan sound } \\
\text { effect type the keyboard }\end{array}$ \\
\hline 9 & $\begin{array}{l}\text { (Long Shot, MediumShot, Close } \\
\text { Up) } \\
\text { 00:00:51:01-00:01:09:00 }\end{array}$ & $\begin{array}{l}\text { Sampah yang } \\
\text { menumpuk dipinggir } \\
\text { sungaiCiliwung }\end{array}$ & Musik instrumen \\
\hline 10 & $\int_{R}^{P}$ & $\begin{array}{l}\text { Sebarangan di } \\
\text { pinggir jalan }\end{array}$ & $\begin{array}{l}\text { Permasalahan plastik di } \\
\text { Indonesia merupakan masalah } \\
\text { yang belum terselesaikan } \\
\text { hingga saat ini. }\end{array}$ \\
\hline
\end{tabular}




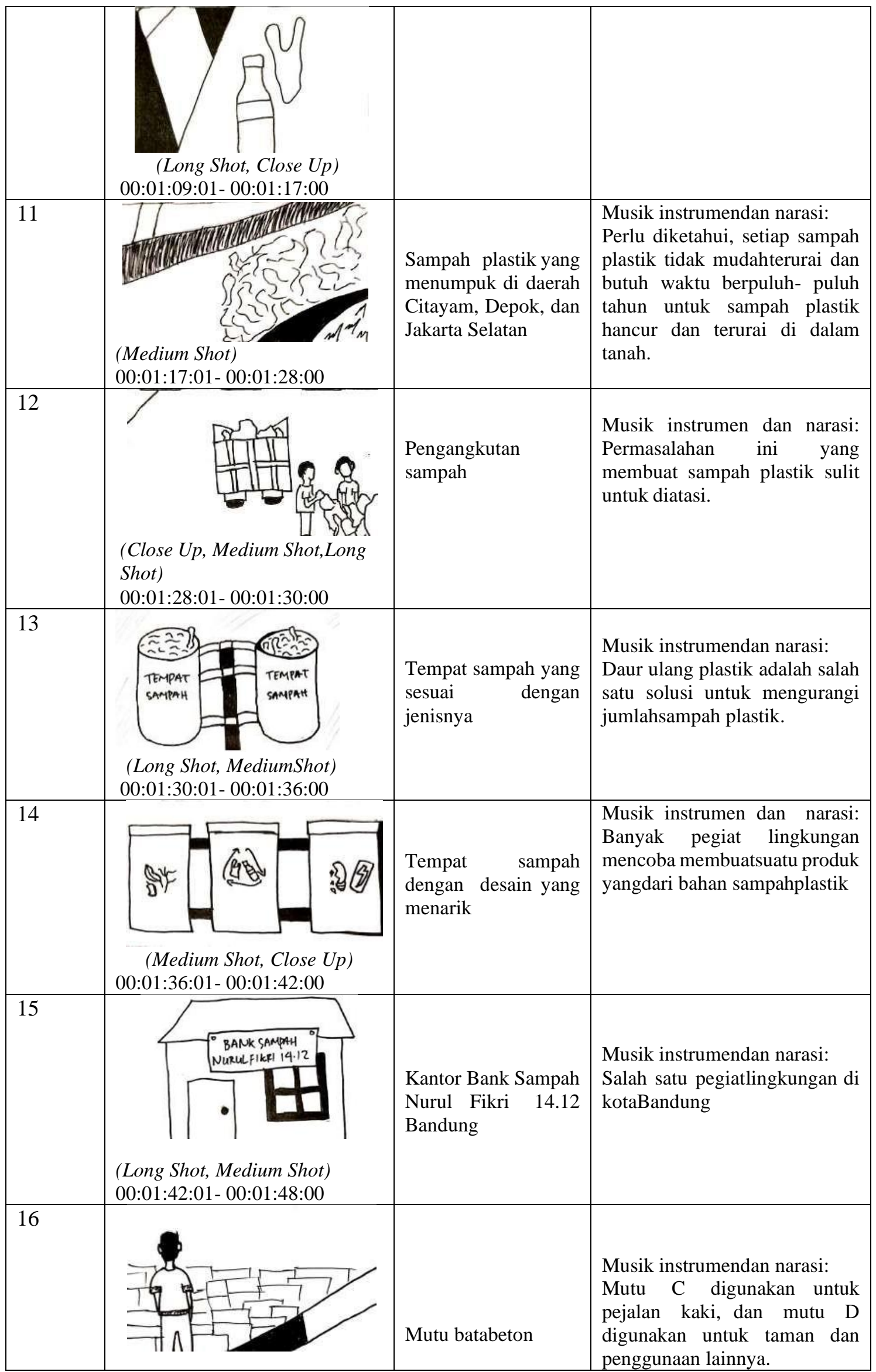




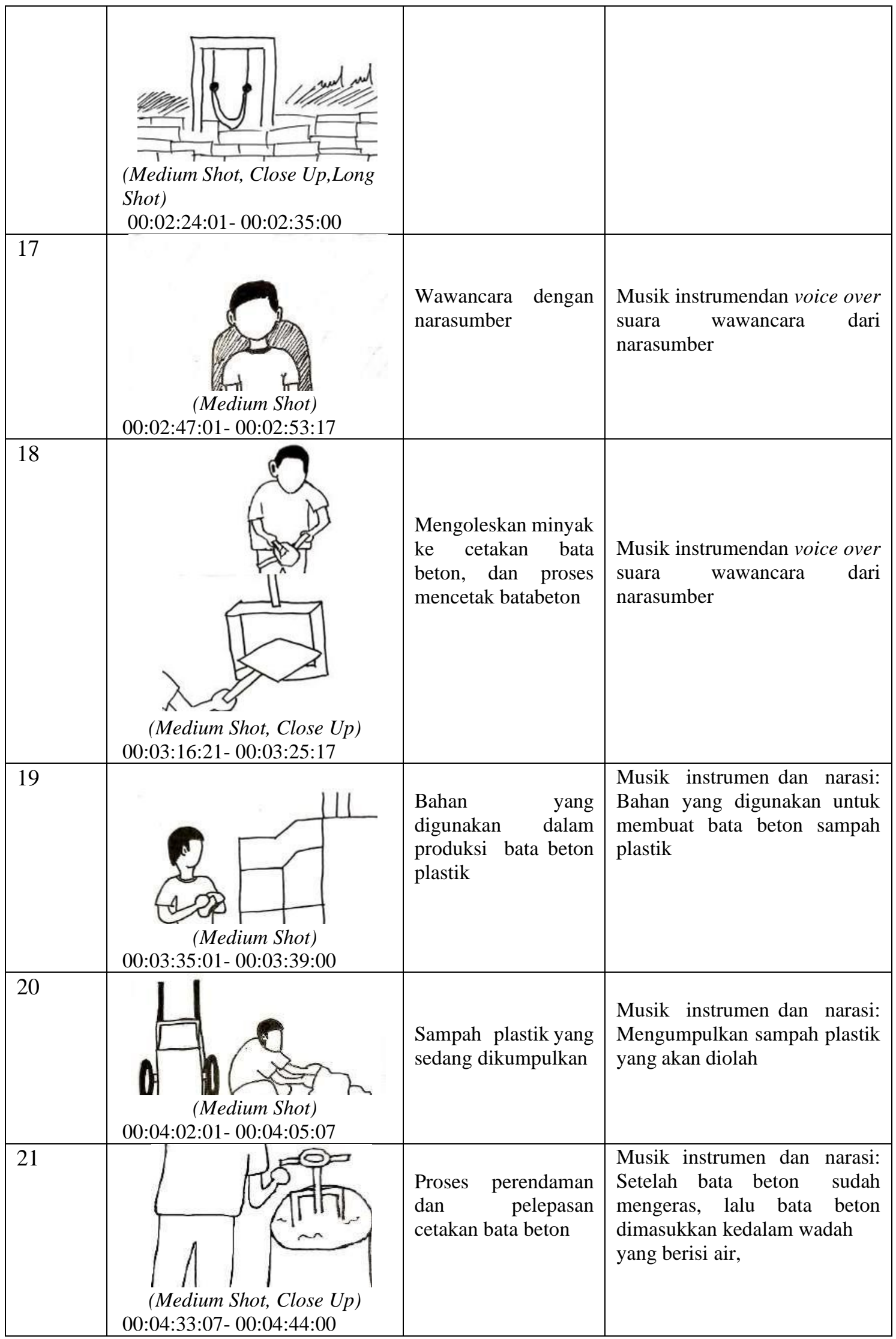




\begin{tabular}{|c|c|c|c|}
\hline 22 & $\begin{array}{l}\text { (Medium Shot) } \\
\text { 00:04:57:01-00:04:59:00 }\end{array}$ & $\begin{array}{l}\text { Wawancara dengan } \\
\text { narasumber }\end{array}$ & $\begin{array}{l}\text { Musik instrumen } \\
\text { Voice over Suara wawancara } \\
\text { dari narasumber }\end{array}$ \\
\hline 23 & 00:05:43:01-00:05:49:00 & $\begin{array}{l}\text { Bata beton yang } \\
\text { dipakai ditrotoar }\end{array}$ & $\begin{array}{l}\text { Musik instrumendan narasi: } \\
\text { Lebih tahan lama dibanding } \\
\text { bata beton pada umumnya. }\end{array}$ \\
\hline 24 & 00:05:49:01- 00:05:52:00 & Proses produksi & $\begin{array}{l}\text { Musik instrumen dan narasi: } \\
\text { Sampah plastik, dapat menjadi } \\
\text { kawan }\end{array}$ \\
\hline 25 & 00:05:57:01-00:06:03:00 & $\begin{array}{l}\text { Menampilkan mesin } \\
\text { penghancur plastik } \\
\text { dan proses produksi }\end{array}$ & $\begin{array}{l}\text { Musik instrumen dan narasi: } \\
\text { Seperti mendaur ulang dan } \\
\text { menciptakan peluang dengan } \\
\text { produk yang dihasilkan dari } \\
\text { daur ulang sampahplastik }\end{array}$ \\
\hline 26 & $\begin{array}{l}\text { (Medium Shot, Long ShotClose } \\
\text { Up) } \\
\text { 00:06:03:01-00:06:11:00 }\end{array}$ & $\begin{array}{l}\text { Proses produksi bata } \\
\text { beton plastik }\end{array}$ & $\begin{array}{l}\text { Musik instrumendan narasi: } \\
\text { Pada akhirnya, plastik yang } \\
\text { sering kita gunakan dalam } \\
\text { sehari-hari, dapat membawa } \\
\text { masalah di kemudian hari } \\
\text { tanpa, kita sadari. }\end{array}$ \\
\hline 27 & $y$ & $\begin{array}{l}\text { Menampilkan taman } \\
\text { dan dua orang yang } \\
\text { sedang produksi bata } \\
\text { beton plastik }\end{array}$ & $\begin{array}{l}\text { Musik instrumendan narasi: } \\
\text { Lalu hal besar yang dapat kita } \\
\text { lakukan, adalah menciptakan } \\
\text { inovasi produk daur ulang } \\
\text { sampah plastik }\end{array}$ \\
\hline
\end{tabular}




\begin{tabular}{|c|c|c|c|}
\hline & $\begin{array}{l}\text { (Close Up, Medium Shot) } \\
\text { 00:06:32:01- 00:06:40:00 }\end{array}$ & & \\
\hline 28 & 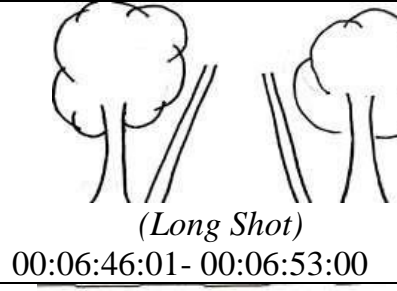 & Pepohonanyang asri & $\begin{array}{l}\text { Musik instrumendan narasi: } \\
\text { Kita bisa melakukannya. } \\
\text { Mewujudkan lingkungan } \\
\text { bersih,sehat dan asri }\end{array}$ \\
\hline 29 & $\begin{array}{c}\text { Terimakasin Kepada: } \\
\text { Allah SwT } \\
\text { OrangTua } \\
\text { Dosen-Dosen UNINDRA } \\
\text { Teman - teman } \\
\text { 00:06:53:01- 00:07:20:00 }\end{array}$ & Credit tittle & Musik instrumen \\
\hline
\end{tabular}

\section{Hasil Perancangan}

Perancangan film dokumenter menjadi media utama dalam menyampaikan informasi dan dapat mendorong masyarakat untuk tertarik dalam mengelola sampah plastik sehingga sampah plastik dapat dijadikan suatu produk seperti bata beton yang berbahan dasar dari sampah plastik.

a. Film Dokumenter Bata Beton Berbahan Dasar Sampah Plastik sebagai Bahan Bangunan Ramah Lingkungan

b. Judul film

c. Durasi

: Sampah plastik, kawan atau lawan?

d. Jenis software

: 07.20

e. Format film

: Adobe Premiere CC

f. Frame size

: MP4

: 16:9 (1920x1080) pixels full $\mathrm{HD}$

Di bagian awal film menampilkan judul film dokumenter dengan menggunakan teks berwarna jingga dan background hitam dan membahas tentang plastik yang digunakan dalam sehari-hari.

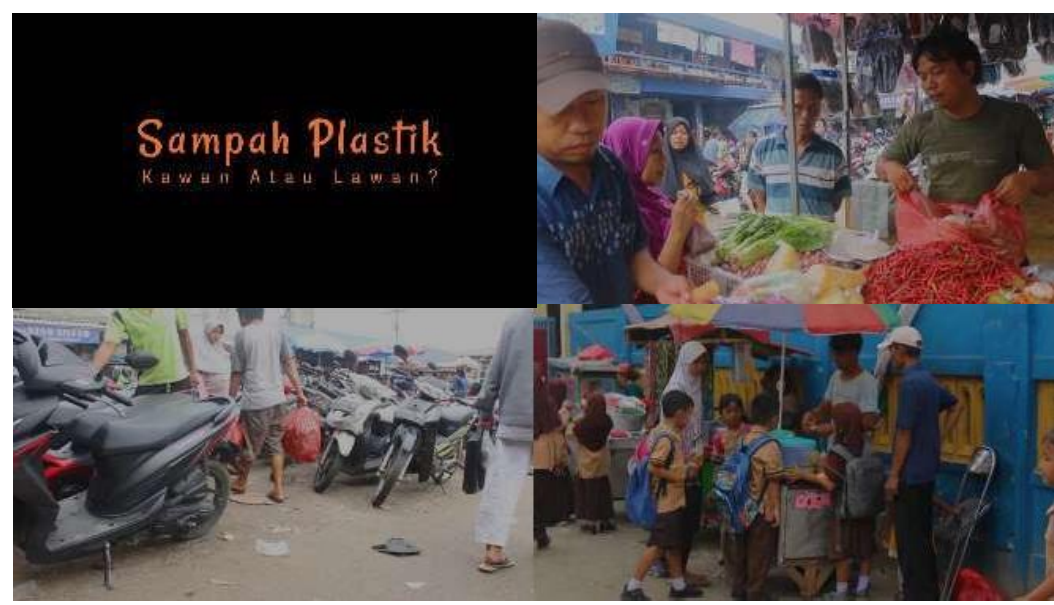

Gambar 4 Bagian Pembuka

Pada bagian isi film menampilkan permasalahan sampah plastik di Indonesia, penggunaan bata beton, bahan dan alat yang digunakan untukpembuatan bata beton plastik, cara pembuatan bata beton plastik serta jenis-jenis bata beton plastik. 


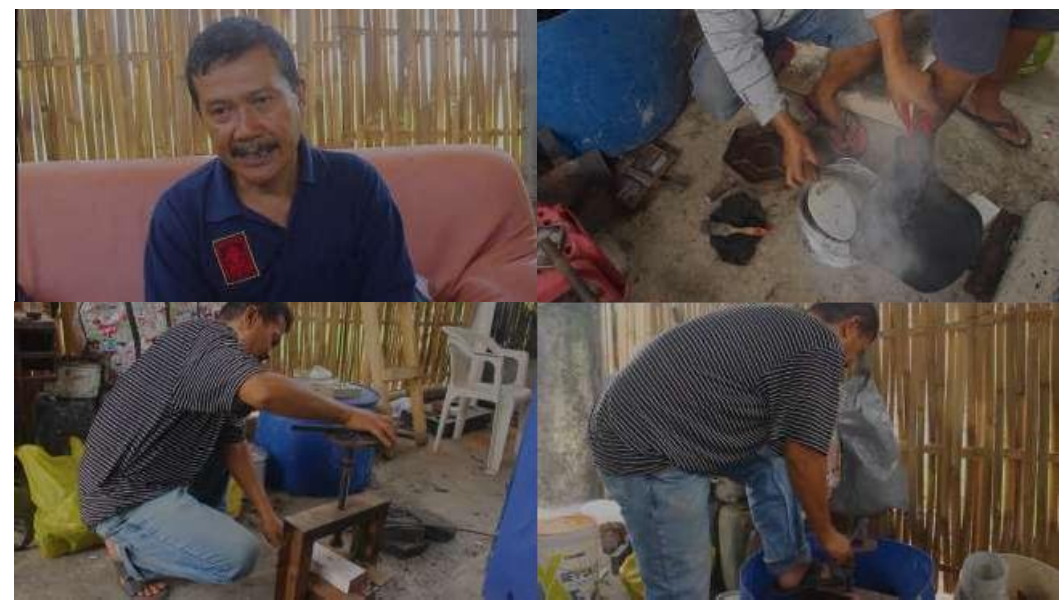

Gambar 5 Bagian Isi

Bagian penutup film, menampilkan pesan ajakan untuk masyarakatagar ikut serta dalam menjaga lingkungan dan mengelola sampah plastiksehingga dapat menjadi produk yang memiliki nilai jual.

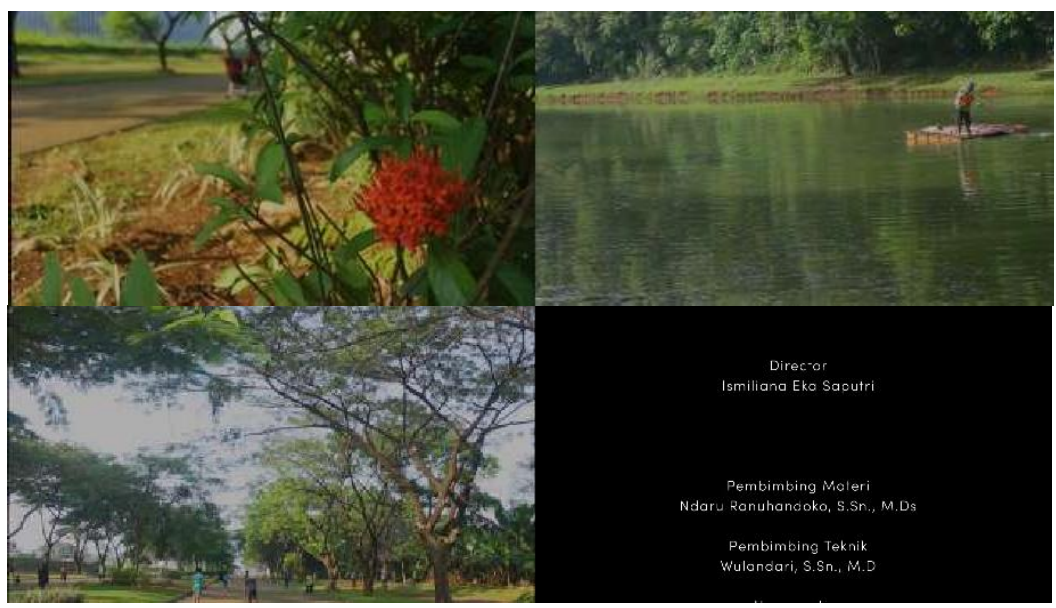

Gambar 6. Bagian Penutup

\section{SIMPULAN}

Permasalahan sampah plastik di Indonesia adalah masalah yang tak kunjung usai dalam beberapa tahun terakhir. Sampah plastik masih banyak ditemui di berbagai tempat seperti di jalan, sungai, laut, gunung dan lainnya. Kesadaran masyarakat yang masih minim dalam menjaga dan mengelola sampah plastik menjadi masalah yang kompleks. Ada beberapa alternatif untuk mengurangi sampah plastik, salah satunya ialah dengan cara daur ulang sampahplastik. Bata beton berbahan dasar sampah plastik adalah salah satu produk daur ulang sampah plastik yang mampu mengurangi sampah plastik yang terdapat di lingkungan sekitar. Dengan melakukan inovasi, sampah plastik yangawalnya menjadi masalah bisa dimanfaatkan menjadi sesuatu yang berguna danmenciptakan produk yang memiliki nilai jual.

Dalam perancangan film dokumenter ini, dimulai dengan menentukan segmentasi target audiens yang ingin dituju sehingga film dokumenter yang akan dibuat sesuai dengan target audiens. Ada beberapa proses tahapan yang dilalui dimulai dari pra produksi dengan menentukan jalan cerita, membuat storyline dan storyboard. Lalu tahap produksi yaitu, proses pengambilan gambar dengan beberapa teknik. Terakhir tahap pasca produksi meliputi, editing film, melakukan dubbing dengan suara narator dan mixing dengan back sound yang sudah ditentukan dan yang sesuai dengan film yang ditampilkan. Dalam proses tahapan pembuatan film dan segmentasi 
yang telahdisesuaikan dengan target, diharapkan agar audiens (masyarakat) dapat memahami film dokumenter yang akan dibuat dan ikut tertarik untuk menjaga lingkungan dan mengelola sampah plastik.

\section{DAFTAR PUSTAKA}

Amran, Y. (2015). Pemanfaatan limbah plastik untuk bahan tambahan pembuatan paving block sebagai alternatif perkerasan pada lahan parkir di Universitas Muhammadiyah Metro. Jurnal Program Studi Teknik Sipil, Vol. 4 (2), 125-129. https://www.ojs.ummetro.ac.id/index.php/tapak/article\%0A/view/143\%0A

Anggito, A., \& Setiawan, J. (2018). Metode penelitian kualitatif. CV. Jejak.

Candraditya, V. J. (2018). Soroti masalah pengelolaan sampah, ini kata Mendagri. Online. https://www.tribunnews.com/nasional/2018/04/04/soroti-masalah- pengelolaan-sampahini-kata-mendagri

Gusniar, I. N. (2018). Metode pembuatan paving block segi enam berbahan sampah plastik dengan mesin injection molding. Jurnal Barometer, Vol. 3 (2), 130-133. https://journal.unsika.ac.id/index.php/barometer/article/view/13

Hamidah, L. (2018). Teknologi pengolahan sampah skala besar: Ecobrick, minyak pirolisis, batako dan paving block, dan campuran aspal. Desa Pustaka Indonesia.

Mudjiono, Y. (2011). Kajian semiotika dalam film. Jurnal Ilmu Komunikasi, Vol. 1 (1), 125-138. http://jurnalilkom.uinsby.ac.id/index.php/jurnalilkom/article/view/10

Purwaningrum, P. (2016). Upaya mengurangi timbunan sampah plastik di lingkungan. Jurnal Teknologi Perkotaan Dan Lingkungan Indonesia, Vol. 8 (2), 141-147. https://www.trijurnal.lemlit.trisakti.ac.id/urbanenvirotech/article/view/142 1

Putra, H. P., \& Yuriandala, Y. (2010). Studi pemanfaatan sampah plastik menjadi produk dan jasa kreatif. Jurnal Sains Dan Teknologi Lingkungan, Vol. 2 (1), 21-31. https://www.neliti.com/publications/129358/studi- pemanfaatan-sampah-plastik-menjadiproduk-dan-jasa-kreatif

Sibuea, A. F. (2013). Pemanfaatan Limbah botol plastik sebagai bahan eco plafie (economic plastic fiber) paving block yang berkonsep ramah lingkungan dengan uji tekan, uji kejut dan serapan air. Universitas Sumatera Utara, Medan.

Sumarni, S. (2016). Ilmu bahan bangunan. Yuma Pressindo.

Sundawa, O. P. ., \& Pramushinta, I. A. . (2019). Sosisalisasi dan demonstrasi pembuatan paving block dari sampah plastik. Jurnal Penamas Adi Buana, Vol. 2 (2), 17-19. http://jurnal.unipasby.ac.id/index.php/penamas/article/view/1833 